\title{
Flashover Characteristics of Silicone Rubber Sheets under Various Environmental Conditions
}

\author{
Arshad ${ }^{1, *}$, Azam Nekahi ${ }^{1}$, Scott G. McMeekin ${ }^{1}$ and Masoud Farzaneh ${ }^{2}$ \\ 1 School of Engineering and Built Environment, Glasgow Caledonian University, Glasgow G4 0BA, UK; \\ azam.nekahi@gcu.ac.uk (A.N.); scott.mcmeekin@gcu.ac.uk (S.G.M.) \\ 2 Canada Research Chair on Atmospheric Icing Engineering of Power Networks (INGIVRE), \\ Université du Québec à Chicoutimi, Québec, QC G7H 2B1, Canada; Masoud_Farzaneh@uqac.ca \\ * Correspondence: arshad@gcu.ac.uk; Tel.: +44-74-7871-3346
}

Academic Editor: Issouf Fofana

Received: 4 July 2016; Accepted: 19 August 2016; Published: 26 August 2016

\begin{abstract}
Silicone rubber insulators are replacing the conventional ceramic and porcelain insulators rapidly in power transmission and distribution industry. Very limited field knowledge is available about the performance of silicone rubber insulators in polluted and contaminated environments and therefore need further investigation. A comprehensive analysis of silicone rubber sheets (intended for coating outdoor insulators) was carried out in this paper based on experimental results. The main performance parameters analyzed were arc inception voltage and flashover voltage. Dependence of these parameters on equivalent salt deposit density (ESDD), non-soluble salt deposit density (NSDD), relative humidity, ambient temperature, fog rate, dry band formation, dry band location and number of dry bands were investigated extensively. Insulator orientation and its effect on performance were also studied. The authors believe that this paper will provide a comprehensive knowledge about the flashover characteristics of silicone rubber insulators under humid, contaminated and dry band conditions. These results could be used in the selection and design of silicone rubber insulators for polluted environments.
\end{abstract}

Keywords: silicone rubber; arc inception voltage; pollution; flashover; dry bands; humidity; ambient temperature

\section{Introduction}

Outdoor insulators play a vital role in the reliability of power transmission and distribution. Performance of outdoor insulators is influenced by many factors: environmental, electrical and mechanical. One of the most important factors influencing the performance of outdoor insulators is air pollution. It is revealed in literature that in the United State insulators that performed well at $60 \mathrm{kV}$ in clean air, failed at $11 \mathrm{kV}$ near the coastline [1]. The stable and reliable operation of power system is dependent on the pollution flashover performance of outdoor insulators. With the advancement of manufacturing techniques, new materials have been developed to improve the pollution performance of outdoor insulators. The introduction of polymeric materials initially as outdoor insulators were not because of the poor performance of ceramic insulators but due to the other benefits polymeric insulators offer, e.g., lower cost, low weight, improved pollution performance, etc. [2,3]. Although polymeric insulators offer various advantages as compared to porcelain and glass insulators, their organic nature make them vulnerable to ageing and degradation.

The many advantages of polymeric materials over porcelain and glass insulators are due to their unique property of hydrophobicity. The hydrophobic behavior of polymeric materials resists the formation of a uniform pollution layer along the surface leading to water droplets [4]. Numerical simulation of electric field distribution around the water droplets on the insulator surface revealed 
that electric field intensifies at the junction of water droplet, air and insulating surface [5-7]. Due to the high electric field stress at the edges of water droplets, deformation of water droplets occurs along the direction of applied electric field [8,9]. The elongation of water droplets in the direction of electric field initiates local arcs and partial discharges. Although partial arcs are usually of low energy, they can damage silicone rubber surfaces if they last for longer duration. These partial arcs and discharges lead to the loss of surface hydrophobicity [10-12]. Loss of hydrophobicity results in uniform water layer along the insulator surface and facilitates the flow of leakage current. The flow of leakage current along the insulator surface leads to Joule heating, dry band formation, local arcs and under certain conditions may lead to flashover.

Pollution performance of outdoor insulators is dependent on various parameters including but not limited to the geographical location where insulators are installed [13-17]. Artificial pollution used in laboratories is either sodium chloride $(\mathrm{NaCl})$ or calcium sulfate $\left(\mathrm{CaSO}_{4}\right)$ in combination with a non-soluble material. The results presented in [13] show that the flashover voltage is dependent on the type of soluble constituents in the pollution layer. It further revealed that according to kinetic theory, heavier ions e.g., $\mathrm{Ca}^{2+}$ will result in high flashover voltage. A similar result was reported in [14] that flashover voltage of outdoor insulators is a function of the chemical composition of pollution material. Researchers in $[18,19]$ derived arc constants $A$ and $n$ for critical flashover voltage and current based on different soluble contaminants.

Effect of non-soluble salt deposit density (NSDD) on flashover characteristics of outdoor insulators have been investigated in [20] and concluded that the particle size of non-soluble material in slurry is the main factor influencing flashover. Based on these results, it was reported in [21] that the flashover voltage of artificially polluted insulator is higher with Tonoko as non-soluble material as compared to Kaolin and Kieselguhr. Recovery of hydrophobicity is also found to be dependent on the type of non-soluble material.

Another important parameter influencing the flashover behavior of outdoor insulators is relative humidity. It was reported in $[22,23]$ that breakdown strength of air gaps increases with increase in relative humidity. In the case of ice-covered insulators, an increase of $3 \%$ was reported in arc inception voltage when the humidity level was changed from low to normal [24]. In the case of polluted polymeric insulators, the results were found to be opposite to that of ice-covered insulators and air gaps. Experimental results of $[25,26]$ show that flashover voltage decreases with increase in relative humidity. Due to the absorption of water molecule on the insulator surface, surface conductivity increases with increase in relative humidity and that can be attributed to decrease in flashover voltage.

Ambient temperature also affects the flashover performance of outdoor insulators. It was reported in [27] that the speed of hydrophobicity recovery is influenced by ambient temperature. An increase in hydrophobicity transfer speed and contact angle was reported with ambient temperature. These results show that an increase in ambient temperature increases the hydrophobicity recovery leading to increase in flashover voltage. Increase in ambient temperature also leads to ageing and degradation of polymeric insulators $[28,29]$ but that was not considered in [27]. It is believed that further investigation into the effect of ambient temperature on pollution flashover of polymeric insulators is necessary considering loss and recovery of hydrophobicity with ambient temperature.

Artificial pollution test on outdoor insulators mostly consider uniform pollution layer on the insulator surface [30-33]. Pollution deposition on insulator surface in field condition is non-uniform and dependent on various parameters, e.g., wind speed and direction, geographical location, insulator geometry and orientation, etc. The non-uniform pollution distribution along the insulator surface leads to non-uniform current density and electric field distribution. This non-uniformity of current density leads to dry regions on the insulator surface called "dry bands". The non-uniformity of pollution distribution and dry band formation has been investigated in the literature [34-37]. In [34], it was reported that dry band formation is a function of power dissipated along the insulator surface. Mathematical models have been developed by various researchers to study the effect of non-uniform pollution on critical flashover voltage [38-40]. Numerical results of electric field distribution showed 
that dry band along the insulator surface acts as an open circuit and all voltage drops occurs along the dry band leading to high electric field intensity at the edges of dry bands [41-43]. Although dry bands formation and their effects on flashover strength of outdoor insulators have been investigated previously in the literature, no experimental results exists on the effect of dry band location, width and number of dry bands on flashover voltage and surface resistance.

\section{Sample Preparation}

Due to the hydrophobic nature of silicone rubber insulators, uniform pollution cannot be applied directly using IEC 60507 [44]. In this study, a modified solid layer method based on IEC 60507 proposed in [45] was used for polluting silicone rubber samples. This method involves pre-conditioning of the insulator surface with dry kaolin to make it hydrophilic. After preconditioning, samples are checked by wettability class to see if the surface is hydrophilic. A wetting agent (Triton X-100) is also used in combination with water, $\mathrm{NaCl}$ and kaolin. All tests were performed on rectangular silicone rubber sheets having dimension of $10 \mathrm{~cm} \times 4 \mathrm{~cm} \times 0.6 \mathrm{~cm}$. Various samples were prepared with different level of equivalent salt deposit density (ESDD), NSDD and dry band configurations. Figure 1 shows the flowchart of pollution application. Sample configuration and dimensions are shown in Figure 2. Figure 3 shows the complete set of samples used for tests. The sample shown in Figure 3a was polluted uniformly and used as a reference point. Values of ESDD were changed according to Table 1 to model different pollution severity levels. Similar to constant value of ESDD, NSDD was changed to study the effect of inert materials on flashover characteristics. Clean bands were created artificially at the ground end, middle part and high voltage end to study the effect of clean and dry bands. This clean strip along the insulator surface is referred as "dry band" hereafter in this paper. The width of dry band was varied from $0.5 \mathrm{~cm}$ to $2.0 \mathrm{~cm}$. Samples having multiple dry bands were also investigated.

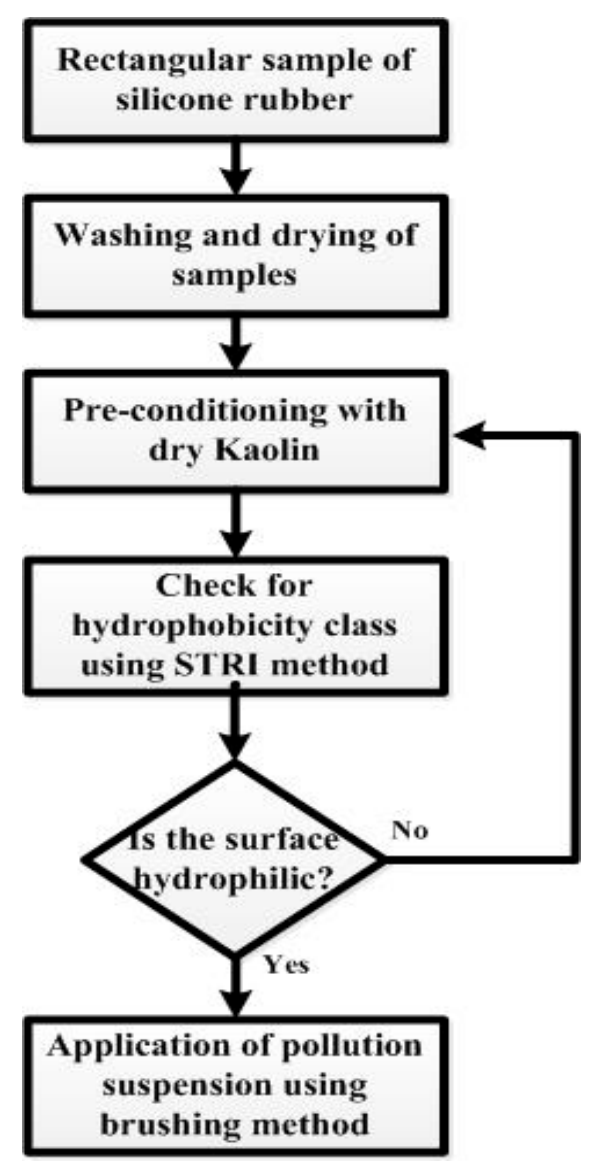

Figure 1. Flowchart of pollution application. 


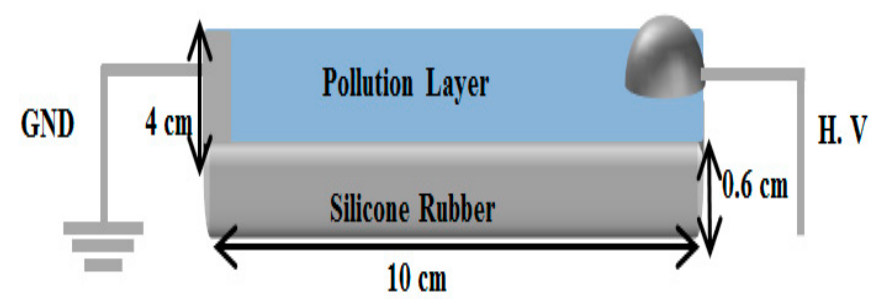

Figure 2. Test sample showing electrode setup and sample dimensions.

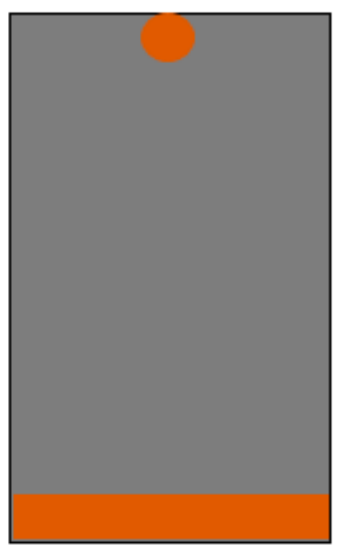

(a)

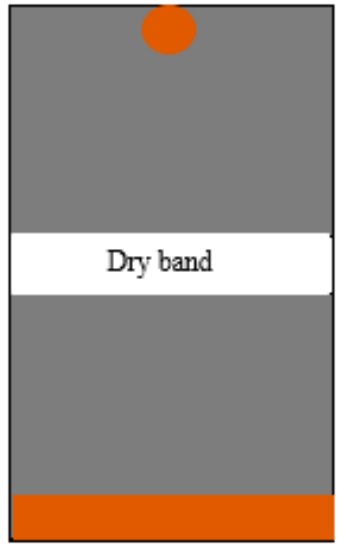

(c)

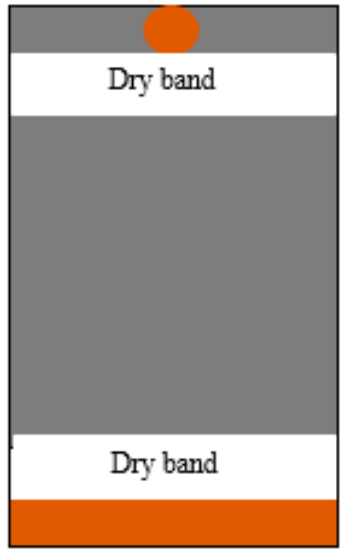

(e)

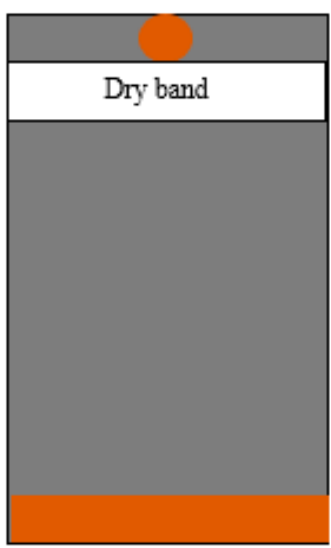

(b)

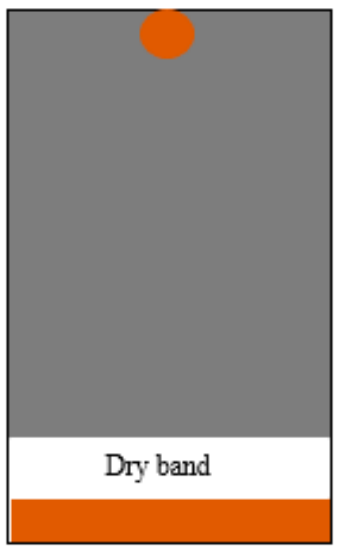

(d)

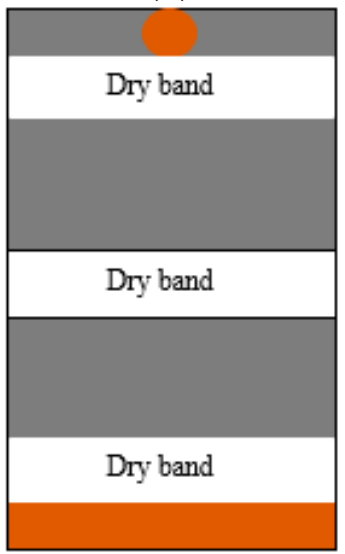

(f)

Figure 3. Test samples: (a) uniform pollution; (b) dry band at HV end; (c) dry band at middle part; (d) dry band at ground end; (e) two dry bands; and (f) three dry bands. 
Table 1. Equivalent salt deposit density (ESDD) and volume conductivity at different pollution severity levels.

\begin{tabular}{ccc}
\hline Pollution Severity & ESDD $\left(\mathrm{mg} / \mathrm{cm}^{2}\right)$ & Volume Conductivity $(\mathrm{S} / \mathrm{m})$ \\
\hline Light & 0.035 & 1.4 \\
Medium & 0.1 & 4 \\
Heavy & 0.2 & 8 \\
Very heavy & 0.4 & 16 \\
\hline
\end{tabular}

\section{Experimental Setup}

A simplified test setup shown in Figure 4 was chosen for experiments. Silicone rubber samples were placed horizontally on an insulated stand made of acrylic glass. The high voltage system used for test consists of a 0-100 kV, $100 \mathrm{kVA}$, and $50 \mathrm{~Hz}$ transformer. Samples were placed in a climate chamber where ambient temperature, humidity and fog rate can be controlled. The maximum test current and over voltage was configured at $1 \mathrm{~A}$ and $50 \mathrm{kV}$. To minimize any unwanted corona, a copper hemisphere electrode of $1.2 \mathrm{~cm}$ diameter was used as a high voltage terminal while copper plate was used as ground terminal. Both electrodes were attached firmly to the insulator surface using copper screws. A capacitive divider was used for measuring voltage while leakage current was measured using current transformer. A LabVIEW based data acquisition system was developed to record the current and voltage waveforms for further processing.

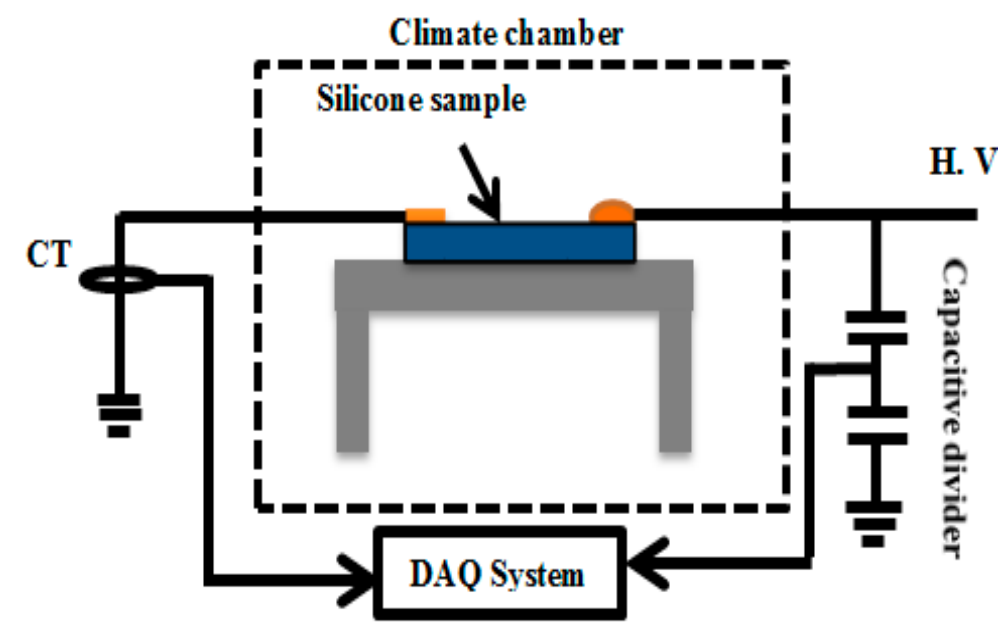

Figure 4. Test setup.

\section{Test Method}

All tests were carried out in a state-of-the-art climate chamber where fog rate, humidity and temperature can be controlled. In most cases, humidity and temperature were set at $80 \%$ and $10{ }^{\circ} \mathrm{C}$, respectively. Samples were placed in the climate chamber and up to $20 \mathrm{~min}$ were allowed for uniform wetting before energizing. Initial tests were carried out on a uniformly polluted sample and flashover voltage was calculated. Once the predicted flashover voltage was determined, other tests were carried out by applying voltage in steps of $5 \%$ of the predicted flashover voltage. Each step was maintained for about $2 \mathrm{~min}$. Partial arcs were observed visually and if no partial arcs appear, voltage was increased to the next step. The voltage at which first partial arc appears was noted down as arc inception voltage. In the case of partial arcs, the voltage was maintained until the arcs disappears or lead to flashover. This procedure was repeated for each sample configuration. Every test was repeated at least 10 times for improved accuracy. After every two tests, sample was removed and pollution was 
re-applied. Equations (1)-(3) were used to obtain minimum flashover voltage and corresponding standard deviation.

$$
\begin{gathered}
V_{\min }=\operatorname{Min}\left(V_{1}, V_{2}, \ldots \ldots \ldots . V_{10}\right) \\
V_{a v}=\frac{\sum_{i=1}^{10} V_{\min }}{N} \\
\sigma(\%)=\sqrt{\frac{\sum_{i=1}^{10}\left(V_{\min }(i)-V_{a v}\right)^{2}}{10} \times \frac{100}{V_{a v}}}
\end{gathered}
$$

Figure 5 shows the flowchart of high voltage test and measurements of arc inception and flashover voltage.

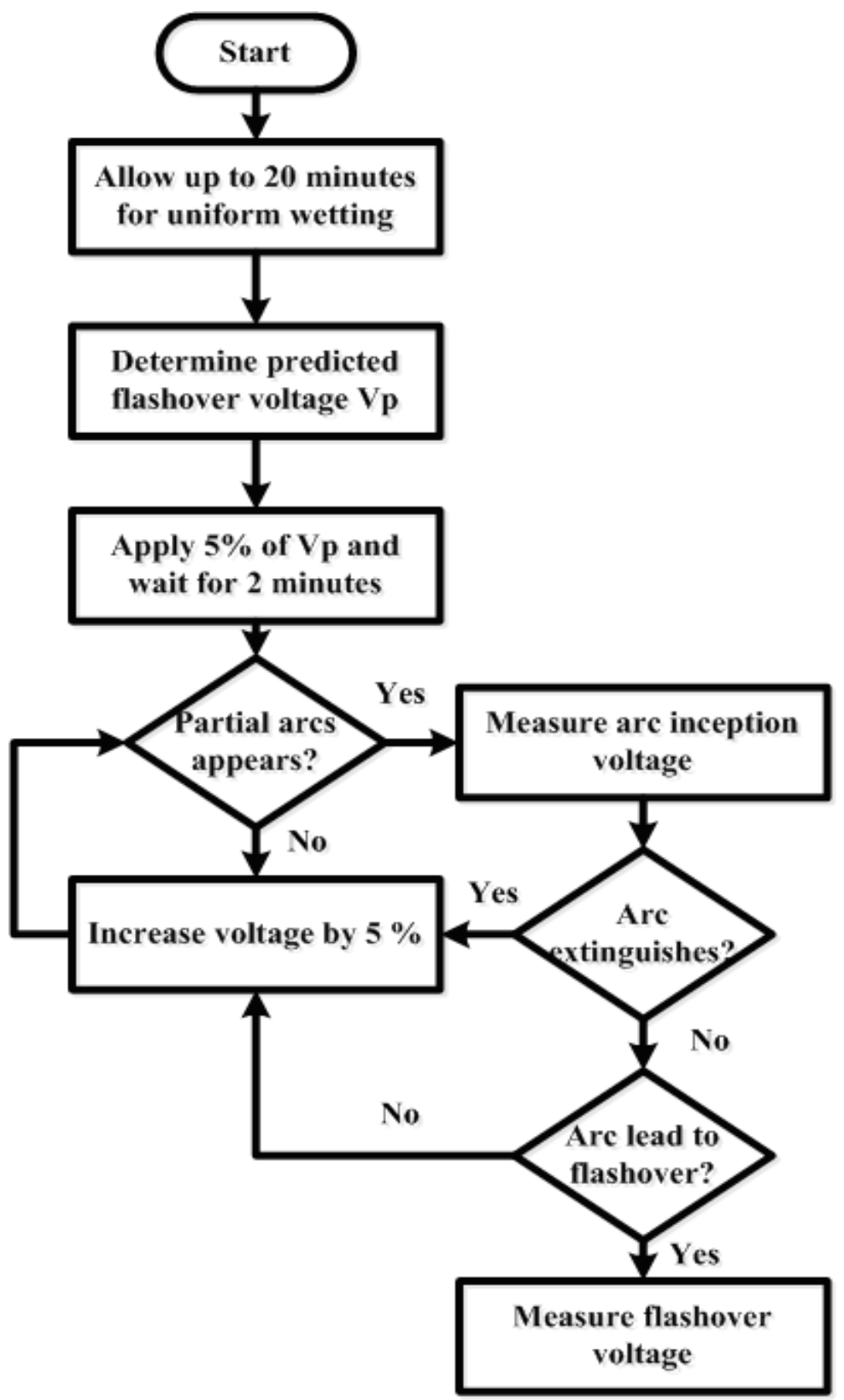

Figure 5. Flowchart of high voltage test method. 


\section{Experimental Results}

\subsection{Arc Inception Voltage}

Arc inception voltage plays a very important role in predicting the flashover strength of outdoor insulators. Furthermore, ageing and degradation of polymeric insulators can also be determined using arc inception voltage. Partial discharge inception voltage of water droplets on a polymeric insulating surface has been investigated in literature $[7,46]$. Experimental results of arc inception voltage for ice-covered insulators are presented in [47] and the dependence of inception voltage on humidity is investigated. Knowledge of arc inception voltage is necessary for understanding arc propagation along the surface of a polluted insulator. In this section, experimental results of arc inception voltage and its dependence on various parameters are presented.

\subsubsection{Influence of Non-Soluble Salt Deposit Density (NSDD)}

The pollution deposited on real insulators surface contains soluble and non-soluble contaminants. The presence of soluble contaminants facilitate the flow of leakage current when dissolve in water. The presence of only non-soluble contaminants may not have influence on leakage current and arc inception voltage but in real conditions some sort of soluble contaminants are always present in pollution layer. In this section, tests were carried out to study the effect of non-soluble and soluble contaminants on the arc inception voltage. Figure 6 shows the relation between arc inception voltage and NSDD for different values of ESDD. Tests were carried out at low humidity level and ambient temperature of $10^{\circ} \mathrm{C}$. Figure 6 shows a decrease in inception voltage with increase in NSDD level.

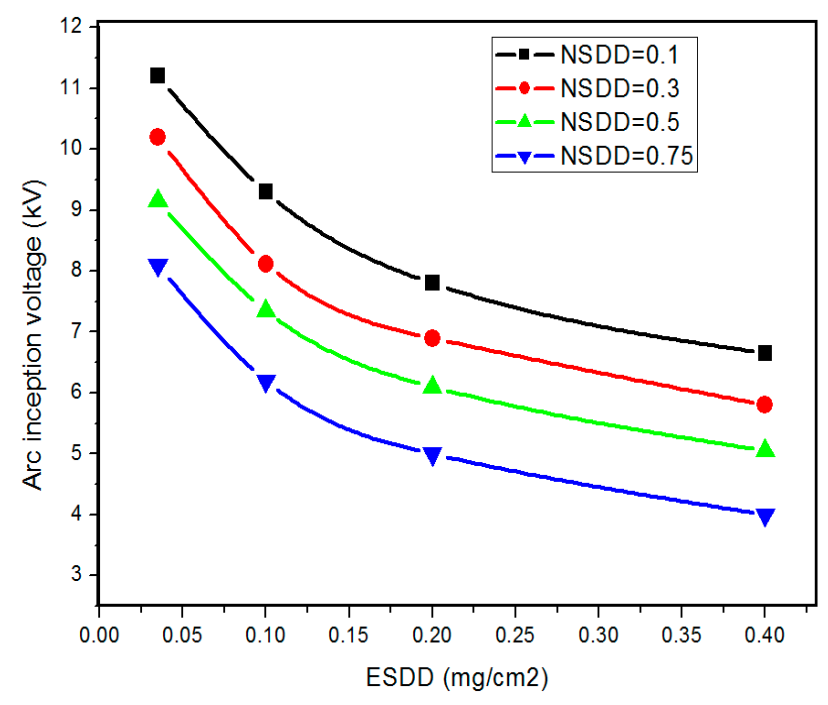

Figure 6. Arc inception voltage at different non-soluble salt deposit density levels, where pollution distribution $=$ uniform, humidity level $=$ low, temperature $=10^{\circ} \mathrm{C}$, and standard deviation $=3.2 \%-5.8 \%$.

\subsubsection{Influence of Relative Humidity}

Outdoor insulators are exposed to various environmental conditions. Relative humidity is dependent on the geographical location, season and climate conditions. For reliable operation of power transmission system, outdoor insulators should have the capability to withstand these changes in climate conditions. Influence of relative humidity on arc inception voltage was studied by varying the humidity in the climate chamber. Tests were carried out at three different humidity levels: low humidity $(40 \%-60 \%)$, moderate humidity $(60 \%-80 \%)$ and high humidity $(80 \%-100 \%)$. Figure 7 shows the arc inception voltage at different humidity and pollution severity levels. The arc inception voltage decreased between 3\% and 5\% as humidity level was changed from low to moderate and moderate to high. 


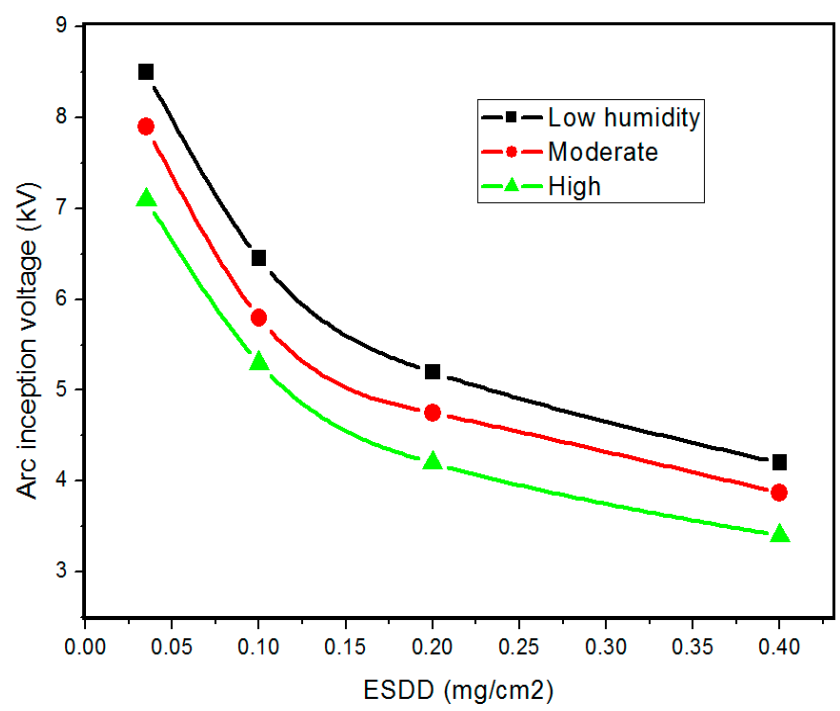

Figure 7. Arc inception voltage at different humidity levels, where pollution distribution = uniform, $\mathrm{NSDD}=0.75 \mathrm{mg} / \mathrm{cm}^{2}$, temperature $=10^{\circ} \mathrm{C}$, and standard deviation $=2.8 \%-6.1 \%$.

\subsubsection{Influence of Temperature}

Ambient temperature affects the hydrophobicity recovery property of polymeric insulators. Furthermore, the conductivity of pollution layer is also a function of temperature. To investigate the effect of ambient temperature on arc inception voltage tests were conducted at four different temperature levels while relative humidity was kept constant. To obtain a steady value of surface hydrophobicity, each sample was placed in climate chamber for $100 \mathrm{~h}$ at the specified temperature before performing the high voltage tests. Figure 8 shows the relation between arc inception voltage and ambient temperature. The arc inception voltage changes from $8 \%-12 \%$ as the temperature was varied from $5{ }^{\circ} \mathrm{C}$ to $20^{\circ} \mathrm{C}$.

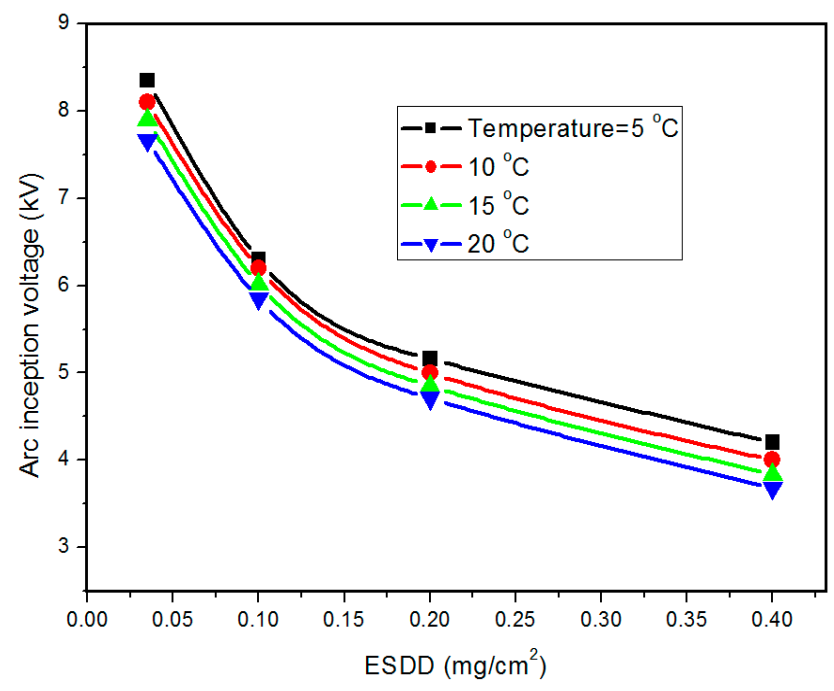

Figure 8. Arc inception voltage at different temperature, where pollution distribution = uniform, $\mathrm{NSDD}=0.75 \mathrm{mg} / \mathrm{cm}^{2}$, humidity level $=$ low, and standard deviation $=3.1 \%-4.7 \%$.

\subsubsection{Influence of Dry Band Location}

The formation of dry bands along insulator surface cannot be eliminated completely. In real outdoor insulators, prediction of the exact location of dry band formation is very complex task and 
requires sophisticated software and hardware. Based on the high electric field intensity near the metal electrodes, it is assumed that dry band will form at the electrode ends. Although this assumption may be true, the formation of dry bands is dependent on other parameters as well as the electric field intensity. To investigate this phenomenon, dry bands of $1 \mathrm{~cm}$ width were inserted at high voltage end, middle part and ground end of the silicone rubber surface. The results obtained show that inception voltage increases with the formation of dry bands. The highest inception voltage was recorded in the case of middle dry band. Relative humidity and ambient temperature were kept constant during the tests. Figure 9 shows the effect of dry band location on arc inception voltage of silicone rubber surfaces.

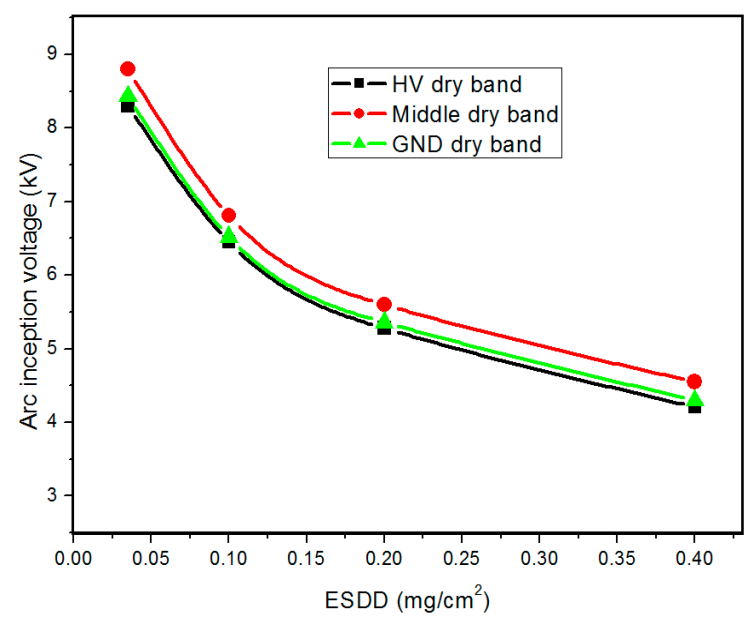

Figure 9. Arc inception voltage at different dry band locations, where NSDD $=0.75 \mathrm{mg} / \mathrm{cm}^{2}$, humidity level $=$ low, temperature $=10^{\circ} \mathrm{C}$, and standard deviation $=3.0 \%-5.15 \%$.

\subsubsection{Influence of Dry Band Width}

The width of dry band along the insulator is a function of current density and corresponding heat generation. In real insulators, width of dry band varies based on leakage current density and pollution pattern. To study the effect of dry band width on arc inception voltage a dry band was inserted at the high voltage end and width was varied from 0.5 to $2.0 \mathrm{~cm}$ in steps of $0.5 \mathrm{~cm}$. Figure 10 shows a relation between dry band width and arc inception voltage. An increase in arc inception voltage was observed as the dry band's width increased.

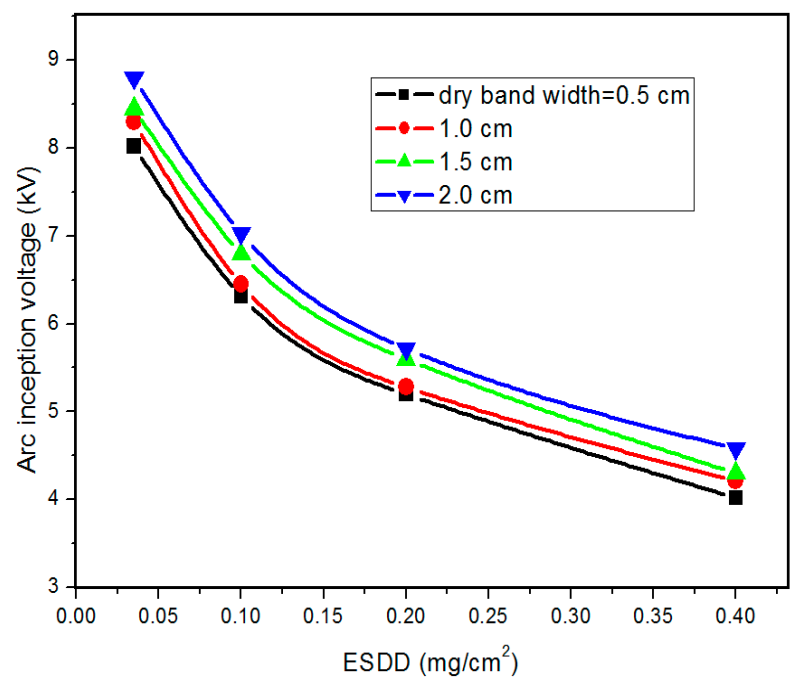

Figure 10. Arc inception voltage at different dry band widths, where NSDD $=0.75 \mathrm{mg} / \mathrm{cm}^{2}$, humidity level $=$ low, temperature $=10{ }^{\circ} \mathrm{C}$, and standard deviation $=3.3 \%-4.6 \%$. 


\subsubsection{Influence of Multiple Dry Bands}

Due to the non-uniform pollution distribution on outdoor insulators, multiple dry bands may form along the insulator surface. The sample configuration in Figure $3 b, e, f$ were used to study the effect of multiple dry bands on arc inception voltage. The dry band's width was kept constant at $1 \mathrm{~cm}$ during the tests. It was noted that, with multiple dry bands, the arc inception voltage increases. Furthermore, it was also observed that the first arc usually appeared at the dry band near the high voltage end and ground end. From visual observation, no arc was observed for dry band at the middle region for the inception voltages reported here. Relation between number of dry bands and corresponding inception voltage is illustrated in Figure 11.

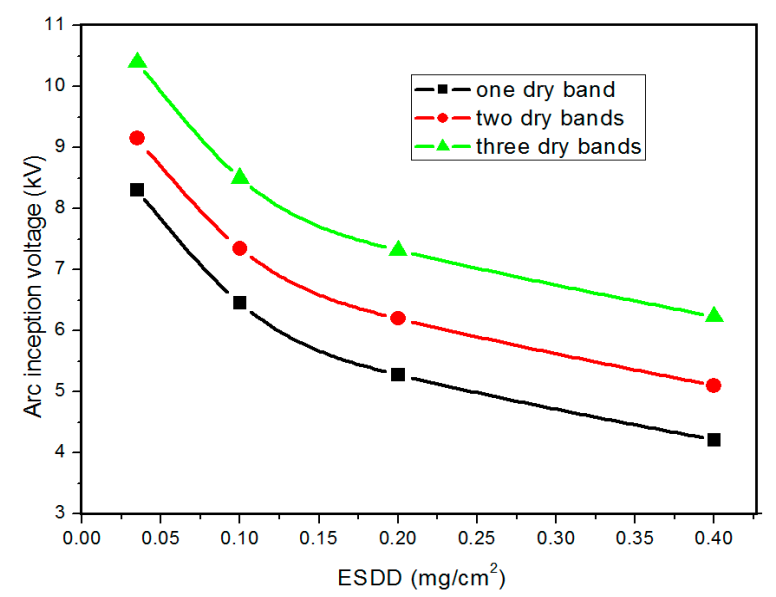

Figure 11. Arc inception voltage at different number of dry bands, where NSDD $=0.75 \mathrm{mg} / \mathrm{cm}^{2}$, humidity level $=$ low, temperature $=10^{\circ} \mathrm{C}$, and standard deviation $=2.1 \%-4.7 \%$.

\subsubsection{Influence of Insulator Orientation}

Insulator orientation also plays important role in the discharge initiation along insulator surface. Generally, insulators are used in either horizontal or vertical position. In this paper, tests were carried out at four different orientations and arc initiation was observed. Figure 12 shows the arc inception voltage at four different orientation angles of a silicone rubber sample. An improvement in arc inception voltage was noted in the case of inclined samples as compared to vertical and horizontal configurations. In the two inclined configurations, the inception voltage was found to be higher for $60^{\circ}$ as compared to $30^{\circ}$.

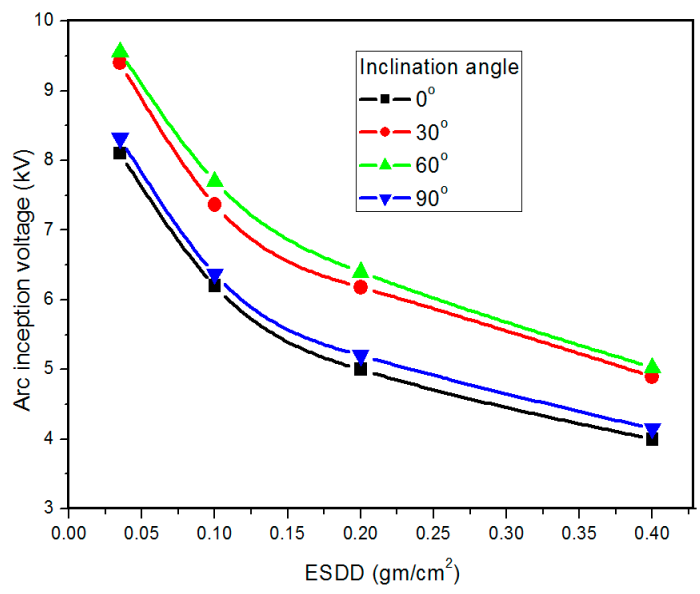

Figure 12. Arc inception voltage at different inclination angles, where pollution distribution = uniform, $\mathrm{NSDD}=0.75 \mathrm{mg} / \mathrm{cm}^{2}$, humidity level $=$ low, temperature $=10{ }^{\circ} \mathrm{C}$, and standard deviation $=2.3 \%-5.1 \%$. 


\subsection{Flashover Voltage}

Pollution flashover is considered one of the most important factors in the design and selection of outdoor insulators. Pollution deposition on outdoor insulators cannot be eliminated completely. Various techniques and models have been developed by many researchers for predicting the flashover voltage of outdoor insulators. Pollution flashover of polymeric insulators is completely different than porcelain and glass insulators [48,49]. In this section, a detailed experimental study was carried out to investigate the effect of various environmental conditions on pollution flashover of silicone rubber surfaces.

\subsubsection{Influence of NSDD}

Pollution deposited on the surface of an insulator is classified into two types: active pollution, which contains minerals, salt fog, metallic particles, etc., and inert pollution, which contains sand, dust and cement particles. In this section, experiments were carried out on uniformly polluted silicone rubber samples to study the flashover behavior under different ESDD and NSDD levels. For every value of ESDD, NSDD was changed from 0.1 to $0.75 \mathrm{mg} / \mathrm{cm}^{2}$. Figure 13 shows the experimental results of flashover voltage at different combination of ESDD and NSDD. A decrease in flashover voltage with ESDD was observed which was reported in our previous investigation [30]. A similar behavior was observed between NSDD and flashover voltage.

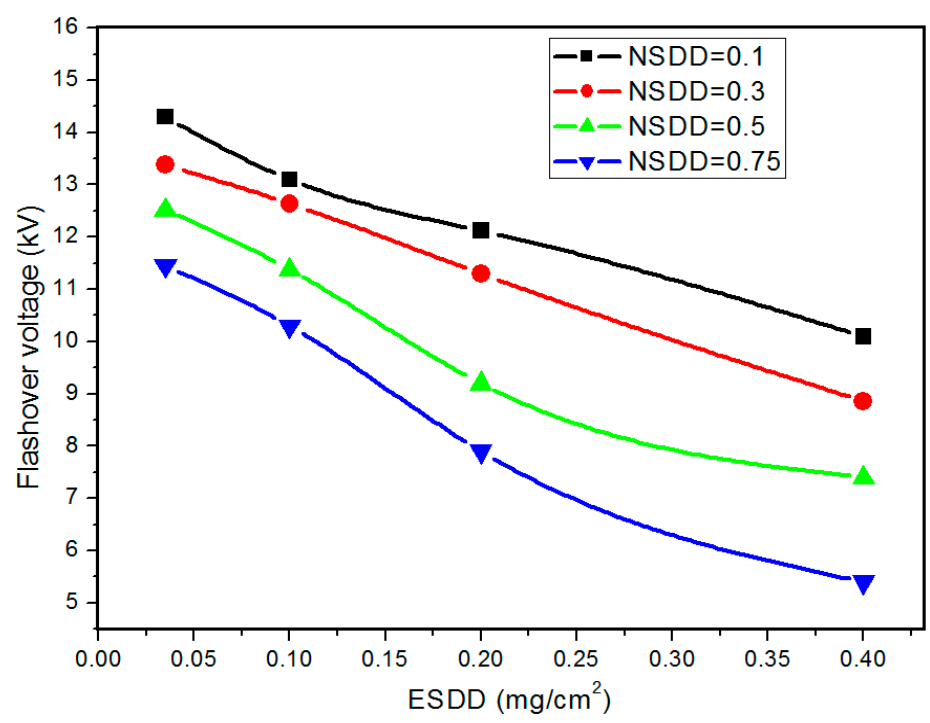

Figure 13. Flashover voltage at different NSDD levels, where pollution distribution = uniform, humidity level $=$ low, temperature $=10^{\circ} \mathrm{C}$, and standard deviation $=2.3 \%-7.2 \%$.

\subsubsection{Influence of Relative Humidity}

As shown in Figure 7, the arc inception voltage decreases with increase in relative humidity. A similar behavior was observed for flashover voltage. This might be due to the decrease in arc propagation velocity at high humidity. For ESDD values of 0.035 and $0.1 \mathrm{mg} / \mathrm{cm}^{2}$, the increase in flashover voltage was found to be linear with arc inception voltage. When the pollution layer conductivity increases (ESDD $=0.4 \mathrm{mg} / \mathrm{cm}^{2}$ ), a sudden decrease in flashover voltage was recorded. It was observed that in the case of heavy pollution, the partial arc lead to sudden flashover in most cases, while, for light pollution, arc mostly disappears after inception. Figure 14 shows the relation between flashover voltage and relative humidity. 


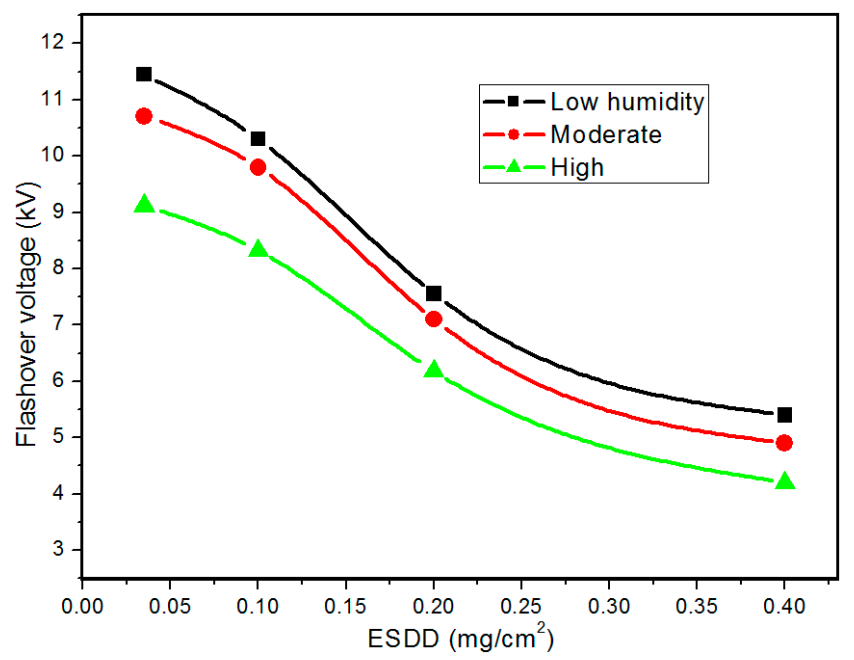

Figure 14. Flashover voltage at different humidity levels, where pollution distribution = uniform, $\mathrm{NSDD}=0.75 \mathrm{mg} / \mathrm{cm}^{2}$, temperature $=10^{\circ} \mathrm{C}$, and standard deviation $=3.1 \%-5.8 \%$.

\subsubsection{Influence of Temperature}

The effect of ambient temperature on flashover characteristics has been investigated in the literature, especially in desert conditions. There are two contradicting statements about the effect of temperature on silicone rubber insulator flashover characteristics. Experimental results reported in [47] concluded that flashover decrease with increase in temperature, which is attributed to the increase in pollution conductivity with temperature. On the other hand, increase in temperature is attributed to an increase in hydrophobicity recovery for silicone rubber insulators in [50,51], which should lead to higher flashover voltages. To investigate this phenomenon, experiments were carried out at four different temperature values and the results obtained are in agreement with [48]. The conclusion drawn in $[50,51]$ may be true if the samples are exposed to higher temperature for longer duration of time. Figure 15 shows the flashover voltage obtained at different combination of temperature and ESDD.

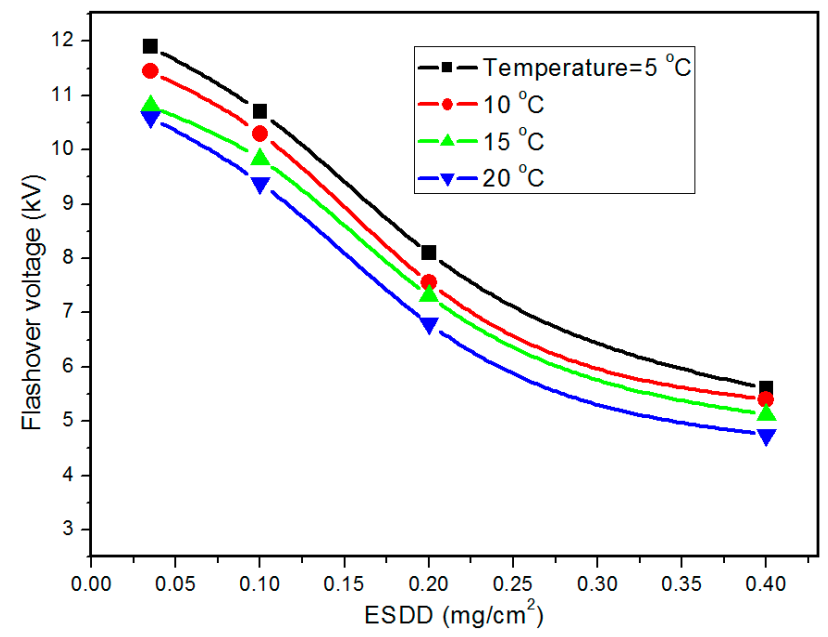

Figure 15. Flashover voltage at different temperature, where pollution distribution = uniform, $\mathrm{NSDD}=0.75 \mathrm{mg} / \mathrm{cm}^{2}$, humidity level $=$ low, and standard deviation $=3.3 \%-6.8 \%$.

\subsubsection{Influence of Dry Band Location}

Generally, dry bands are considered to be at either the high voltage end or ground end due to the high electric field intensity at electrode ends. Although this might be true, dry band formation is 
not only a function of electric field intensity but also pollution density and wetting pattern. In this section, three different configurations were tested having dry bands at high voltage end, ground end and middle part. The results in Figure 16 show that flashover voltage is highest in the case of middle dry band and lowest for dry band at high voltage end. Overall, the flashover voltage increases with the formation of dry bands.

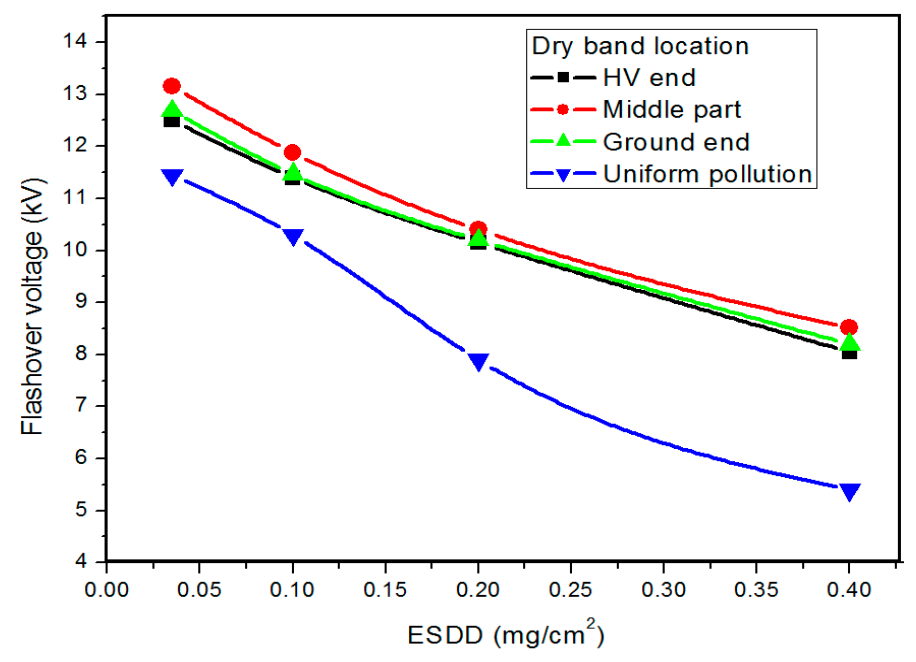

Figure 16. Flashover voltage at different dry band locations, where NSDD $=0.75 \mathrm{mg} / \mathrm{cm}^{2}$, humidity level $=$ low, temperature $=10^{\circ} \mathrm{C}$, and standard deviation $=2.6 \%-6.3 \%$.

\subsubsection{Influence of Dry Band Width}

The dry band's width along the insulator is dependent on various factors including but not limited to the flow of leakage current and electric field distribution. In the case of ice-covered insulators, it was reported in [52] that air gap width is between $6 \%$ and $8 \%$ of leakage distance. This phenomenon cannot be applied directly to polluted insulators due to different flashover process in polluted and ice-covered insulators. In this section experiments were carried out at four different dry band widths and flashover voltage was recorded. The results presented in Figure 17 shows that flashover voltage increases with increase in dry band width.

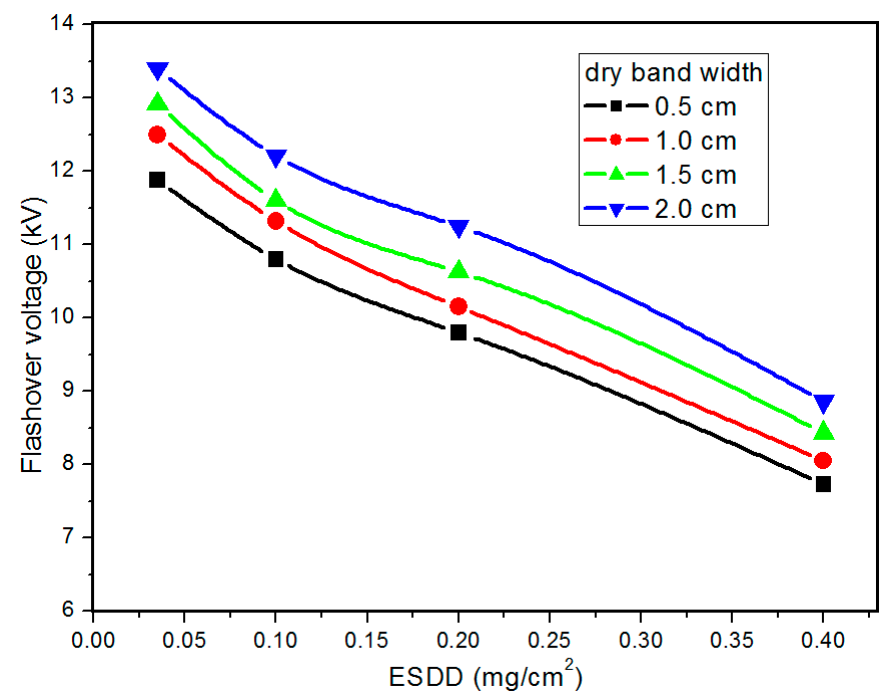

Figure 17. Flashover voltage at different dry band widths. where NSDD $=0.75 \mathrm{mg} / \mathrm{cm}^{2}$, humidity level $=$ low, temperature $=10^{\circ} \mathrm{C}$, and standard deviation $=2.6 \%-5.1 \%$. 


\subsubsection{Influence of Multiple Dry Bands}

In real insulators, multiple dry bands can occur, leading to multiple partial arcs. This phenomenon was investigated using samples configuration in Figure $3 b, e, f$. During inception voltage tests, it was observed that multiple arcs appeared on insulator surface mostly at the high voltage and ground end dry bands. An increase in flashover voltage with multiple dry bands was observed and shown in Figure 18.

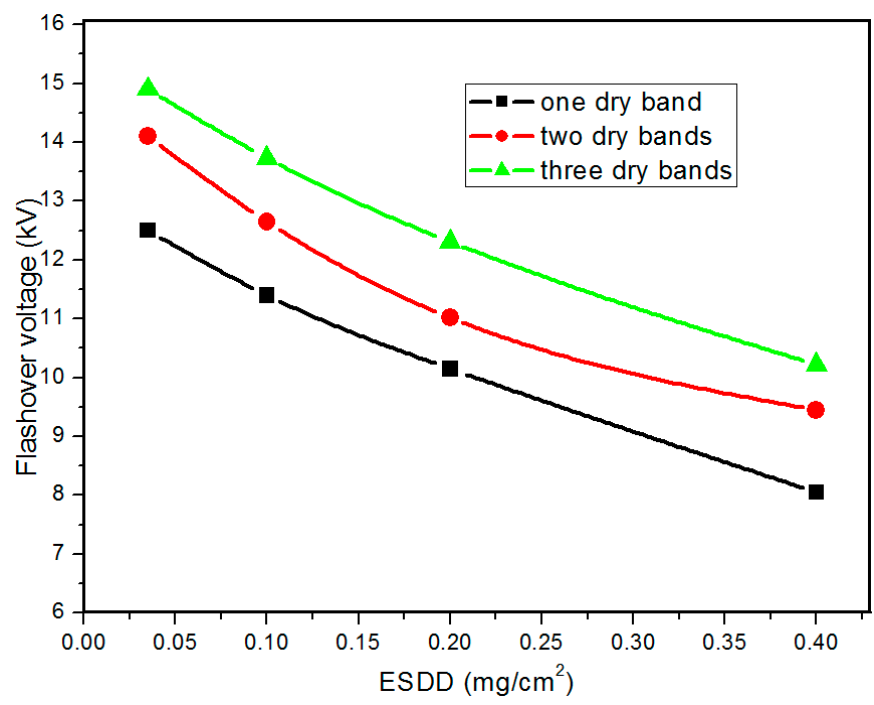

Figure 18. Flashover voltage at different number of dry bands, where NSDD $=0.75 \mathrm{mg} / \mathrm{cm}^{2}$, humidity level $=$ low, temperature $=10{ }^{\circ} \mathrm{C}$, and standard deviation $=2.8 \%-6.5 \%$.

\subsubsection{Influence of Insulator Orientation}

The results of arc inception voltage show that insulator orientation significantly influences the inception voltage. Generally, outdoor insulators are installed either horizontally or vertically depending on the voltage level and insulator type. Flashover voltage of a uniformly polluted silicone rubber sample was investigated by changing the insulator orientation. Tests were carried out at four different angles and results are presented in Figure 19. It was noted that flashover voltage is high in the case of inclined samples as compared to horizontal and vertical configurations.

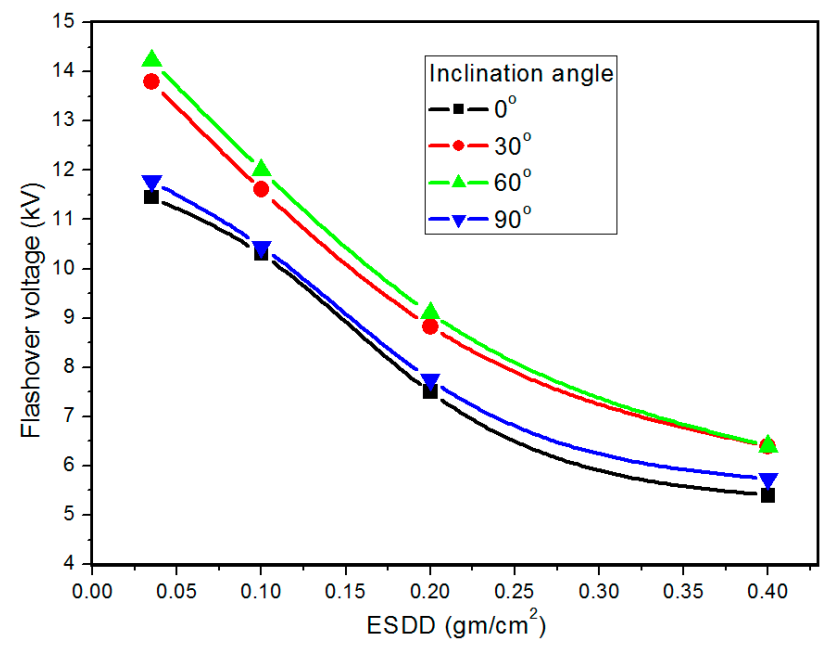

Figure 19. Flashover voltage at different inclination angles, where pollution distribution = uniform, $\mathrm{NSDD}=0.75 \mathrm{mg} / \mathrm{cm}^{2}$, humidity level $=$ low, temperature $=10{ }^{\circ} \mathrm{C}$, and standard deviation $=2.1 \%-6.8 \%$. 


\section{Discussion}

Flashover process of polluted polymeric insulators is affected by many parameters. The most obvious one is the conductivity of the pollution layer. Increase in pollution layer conductivity results in lower inception and flashover voltage as well as surface resistance. Arc inception and flashover voltages decreased by $50 \%$ and $52 \%$, respectively, as the value of ESDD was changed from 0.035 to $0.4 \mathrm{mg} / \mathrm{cm}^{2}$ (Figures 6 and 13). The process of arc inception leading to flashover was also affected by ESDD. With increase in ESDD, the time to flashover from the initial arc inception decrease. The inert material present in the pollution suspension also influences the flashover process. As the value of NSDD was changed from 0.1 to $0.75 \mathrm{mg} / \mathrm{cm}^{2}$, arc inception and flashover voltage decreased by around $20 \%$ for lower values of ESDD (0.035 and 0.1). For higher values of ESDD, the effect of NSDD was found to be more severe and the flashover voltage decreased by $38 \%-45 \%$ (Figures 6 and 13). This might be due to the thicker pollution layer on the insulator surface resulting in more uniform leakage current and decrease in surface resistance. Moreover, as the value of NSDD increases, the pollution layer become more uniform leading to uninterrupted flow of leakage current which result in low flashover voltages. Relative humidity also affects the flashover process of outdoor insulators. For uniform pollution layer, a decrease of $3 \%-5 \%$ in arc inception and flashover voltage was observed when humidity level was changed from low to moderate and moderate to high (Figures 7 and 14). This may be due to the increase in attachment and decrease in photoionization coefficient due to the presence of water. The absorption of water molecule by the dielectric surface with increase in humidity results in uniform water layer and low inception voltages.

Arc inception and flashover voltage change with change in ambient temperature (Figures 8 and 15). It has been reported in literature that conductivity of the pollution layer is a function of temperature [44,47]. An increase in ambient temperature leads to increase in surface conductivity, leakage current and decrease in flashover. This behavior may be different at higher temperatures considering the effect of temperature on loss and recovery of hydrophobicity. Higher temperature may affect the flashover process in different way as reported in [50,51] but due to the limitation of climate chamber temperature could not be increased more than $25^{\circ} \mathrm{C}$.

Dry bands along the insulator surface were found to have great influence on flashover characteristics. As compared to uniform pollution layer, the arc inception and flashover voltage increased by $8 \%$ and $10 \%$, respectively (Figures 9 and 16). This could be due to the high resistance of dry band as compared to pollution layer resistance. Dry band along uniformly polluted insulator surface acts like an open circuit and all voltage drops occurs along the dry bands leading to high electric field at the dry band edges and higher flashover voltages. For middle dry band, the arc appears at the dry band and propagates in both directions leading to flashover. The propagation of partial arc in both direction leads to higher flashover voltage for middle dry band as compared to ground end and high voltage end dry bands.

The increase in the dry band's width from $0.5 \mathrm{~cm}$ to $2.0 \mathrm{~cm}$ resulted in an increase of $8.5 \%$ and $11.5 \%$ in arc inception and flashover voltage respectively (Figures 10 and 17). The increase in voltage drop along the dry band with increase in the dry band's width leads to higher inception and flashover voltages. Multiple dry bands also result in higher flashover and inception voltages as compared to single dry band. The presence of multiple dry bands on the insulator surface leads to multiple partial arcs and higher surface resistance. It was observed during the tests that most of the partial arcs appear at the ground end and high voltage end dry bands because of the high electric field intensity at these locations as compared to middle dry band. The insulator orientation also effects arc inception and flashover voltage. The inclined insulator configurations resulted in $15 \%-20 \%$ higher inception and flashover voltages as compared to horizontal and vertical configurations. The standard deviation was found to be between $2.1 \%$ and $8.1 \%$ in all tests. This variation in standard deviation may be due to the manual application of pollution layer, change in humidity and ambient temperature and wetting rate. 


\section{Conclusions}

Performance of silicone rubber coating materials was evaluated under different environmental and polluted conditions. The two most important evaluation parameters were considered for investigation: arc inception voltage and flashover voltage. The following points were concluded.

1. Inception voltage and flashover voltage decreases with increase in ESDD and NSDD.

2. Increase in humidity and temperature leads to decrease in inception voltage and flashover voltage.

3. Dry bands along the insulator surface leads to increase in arc inception voltage and flashover voltage.

4. The width and number of dry bands along the insulator surface also changes the inception and flashover voltage.

5. Flashover voltage and arc inception voltage were high in the case of middle dry band as compared to high voltage and ground end dry bands.

6. Dry band configuration influences the flashover characteristics.

7. Insulator orientation plays important role in the flashover behavior under polluted conditions.

The experimental results revealed that all environmental conditions have significant influence on insulator performance but the most influencing factors were found to be ESDD and NSDD as compared to humidity, temperature, and insulator orientation. The dry band experiments lead to the conclusion that the formation of dry bands along the insulator surface increases the flashover strength of outdoor insulators. Although this is regarded as a positive improvement, during the experiments, visual observation revealed concentrated discharges along the dry bands, which may damage the insulator surface. In future, we intend to investigate the surface modification of silicone rubber insulators due to the presence of dry bands.

Author Contributions: Arshad and Azam Nekahi designed and performed the experiments. They also analyzed the experimental data and contributed to the paper write up. Scott G. McMeekin and Masoud Farzaneh worked on the analysis part and also helped in experiments design and paper write up. They provided useful input in the original concept and improved the initial idea. The final draft of paper was thoroughly reviewed by Scott G. McMeekin and Masoud Farzaneh.

Conflicts of Interest: The authors declare no conflict of interest.

\section{References}

1. Jolly, D.C. Contamination flashover theory and insulator design. J. Frankl. Inst. 1972, 294, 483-500. [CrossRef]

2. Gorur, R.S.; Cherney, E.A.; Burnham, J.T. Outdoor Insulators; Ravi S. Gorur Inc.: Phoenix, AZ, USA, 1999.

3. Phillips, A. Ceramic vs. polymer (non-ceramic insulators). In Proceedings of the 1st Annual Overhead Transmission Line Equipment, Inspection \& Maintenance Practices Conference, Monterey, CA, USA, March 2002.

4. Phillips, A.J.; Childs, D.J.; Schneider, H.M. Aging of nonceramic insulators due to corona from water drops. IEEE Trans. Power Deliv. 1999, 14, 1081-1089. [CrossRef]

5. Que, W.; Sebo, S.A. Electric field and potential distributions along non-ceramic insulators with water droplets. In Proceedings of the Electrical Insulation Conference and Electrical Manufacturing \& Coil Winding Conference, Cincinnati, OH, USA, 18 October 2001; pp. 441-444.

6. Guan, Z.; Wang, L.; Yang, B.; Liang, X.; Li, Z. Electric field analysis of water drop corona. IEEE Trans. Power Deliv. 2005, 20, 964-969. [CrossRef]

7. Nazemi, M.H.; Hinrichsen, V. Experimental investigations on water droplet oscillation and partial discharge inception voltage on polymeric insulating surfaces under the influence of AC electric field stress. IEEE Trans. Dielectr. Electr. Insul. 2013, 20, 443-453. [CrossRef]

8. Macky, W.A. Some investigations on the deformation and breaking of water drops in strong electric fields. Proc. R. Soc. 1931, 133, 565-587. [CrossRef]

9. Katada, K.; Takada, Y.; Takano, M.; Nakanishi, T.; Hayashi, Y.; Matsuoka, R. Corona discharge characteristics of water droplets on hydrophobic polymer insulator surface. In Proceedings of the 6th International Conference on Properties and Applications of Dielectric Materials, Xi'an, China, 21-26 June 2000; pp. 781-784. 
10. Lopes, J.; Jayaram, S.H.; Cherney, E.A. A method for detecting the transition from corona from water droplets to dry-band arcing on silicone rubber insulators. IEEE Trans. Dielectr. Electr. Insul. 2002, 9, $964-971$. [CrossRef]

11. Heger, G.; Vermeulen, H.J.; Holtzhausen, J.P.; Vosloo, W.L. A comparative study of insulator materials exposed to high voltage AC and DC surface discharges. IEEE Trans. Dielectr. Electr. Insul. 2010, 17, 513-520. [CrossRef]

12. Gorur, S.; Chang, J.W.; Amburgey, O.G. Surface hydrophobicity of polymers used for outdoor insulation. IEEE Trans. Power Deliv. 1990, 5, 1923-1933. [CrossRef]

13. Williams, L.J.; Kim, J.H.; Kim, Y.B.; Arai, N.; Shimoda, O.; Holte, K.C. Contaminated insulators-chemical dependence of flashover voltages and salt migration. IEEE Trans. Power Appar. Syst. 1974, 5, 1572-1580. [CrossRef]

14. Holte, C.; Kim, J.H.; Cheng, T.C.; Kim, Y.B.; Nitta, Y. Dependence of flashover voltage on the chemical composition of multi-component insulator surface contaminants. IEEE Trans. Power Appar. Syst. 1976, 95, 603-609. [CrossRef]

15. Ramos, N.G.; Campillo, R.M.T.; Naito, K. A study on the characteristics of various conductive contaminants accumulated on high voltage insulators. IEEE Trans. Power Deliv. 1993, 8, 1842-1850. [CrossRef]

16. Zhang, Z.; Huang, H.; Jiang, X.; Chen, M.; Hu, J. Analysis of the pollution accumulation and flashover characteristics of field aged $110 \mathrm{kV}$ composite insulators. In Proceedings of the 2011 Electrical Insulation Conference (EIC), Annapolis, MD, USA, 5-8 June 2011; pp. 120-124.

17. Slama, E.-A.; Hadi, H.; Flazi, S. Investigation on influence of salts mixture on the determination of flashover discharge constant Part I: A preliminary study. In Proceedings of the 2008 Annual Report Conference on Electrical Insulation and Dielectric Phenomena, Quebec, QC, Canada, 26-29 October 2008; pp. 674-677.

18. Ghosh, P.S.; Chatterjee, N. Polluted insulator flashover model for ac voltage. IEEE Trans. Dielectr. Electr. Insul. 1995, 2, 128-136. [CrossRef]

19. Slama, E.-A.; Beroual, A.; Hadi, H. Analytical computation of discharge characteristic constants and critical parameters of flashover of polluted insulators. IEEE Trans. Dielectr. Electr. Insul. 2010, 17, 1764-1771. [CrossRef]

20. Matsuoka, R.; Kondo, K.; Naito, K.; Ishii, M. Influence of nonsoluble contaminants on the flashover voltages of artificially contaminated insulators. IEEE Trans. Power Deliv. 1996, 11, 420-430. [CrossRef]

21. Gautam, K.; Yamazaki, T.; Yamada, K.; Matsushita, S.; Sakanishi, K.; Matsuoka, R. Effect of non-soluble contaminants on the flashover voltages of hydrophobic polymer insulators. In Proceedings of the 2006 IEEE 8th International Conference on Properties \& Applications of Dielectric Materials, Bali, Indonesia, 26-29 June 2006; pp. 534-537.

22. Kuffel, E. Electron attachment coefficients in oxygen, dry air, humid air and water vapour. Proc. Phys. Soc. 1959, 74, 297. [CrossRef]

23. Harada, T.; Aihara, Y.; Aoshima, Y. Influence of humidity on lightning and switching impulse flashover voltages. IEEE Trans. Power Appar. Syst. 1971, 4, 1433-1442. [CrossRef]

24. Farokhi, S.; Nekahi, A.; Farzaneh, M. Mechanisms and processes of arc propagation over an ice-covered surface. IEEE Trans. Dielectr. Electr. Insul. 2014, 1, 2634-2641. [CrossRef]

25. Zheng, J.C.; Wang, Z.; Liu, Y.W. Influence of humidity on flashover in air in the presence of dielectric surfaces. In Proceedings of the 1993 IEEE Region 10 Conference on Computer, Communication, Control and Power Engineering, Beijing, China, 19-21 October 1993; pp. 443-449.

26. Arshad; Nekahi, A.; McMeekin, S.G.; Farzaneh, M. Performance comparison of silicone rubber and EPDM insulators in humid and contaminated environments. In Proceedings of the International Conference on Dielectrics, Montpellier, France, 3-7 July 2016.

27. Zhao, C.-L.; Zhu, M.; Mei, H.; Wang, L.; Guan, Z. Influence of environmental factors on hydrophobicity transfer property of silicone rubber material. In Proceedings of the 2015 IEEE Electrical Insulation Conference (EIC), Seattle, WA, USA, 7-10 June 2015; pp. 596-599.

28. Khan, Y.; Qureshi, M.I.; Malik, N.H.; Al-Arainy, A.A. Performance of composite insulators in simulated environmental conditions related to central region of Saudi-Arabia. In Proceedings of the 2006 International Conference on Emerging Technologies, Peshawar, Pakistan, 13-14 November 2006; pp. 378-384. 
29. Khan, Y. Degradation of high voltage polymeric insulators in arid desert's simulated environmental conditions. Am. J. Eng. Appl. Sci. 2009, 2, 438-445. [CrossRef]

30. Arshad; Nekahi, A.; McMeekin, S.G.; Farzaneh, M. Investigating flashover behaviour of silicone rubber insulators under contaminated conditions. In Proceedings of the 2015 IEEE Conference on Electrical Insulation and Dielectric Phenomena (CEIDP), Ann Arbor, MI, USA, 18-21 October 2015; pp. 856-859.

31. Dong, B.; Jiang, X.; Hu, J.; Shu, L.; Sun, C. Effects of artificial polluting methods on AC flashover voltage of composite insulators. IEEE Trans. Dielectr. Electr. Insul. 2012, 19, 714-722. [CrossRef]

32. Gençoğlu, T.; Cebeci, M. The pollution flashover on high voltage insulators. Electr. Power Syst. Res. 2008, 78, 1914-1921. [CrossRef]

33. Wilkins, R. Flashover voltage of high-voltage insulators with uniform surface-pollution films. Proc. Inst. Electr. Eng. 1969, 116, 457-465. [CrossRef]

34. Salthouse, C. Initiation of dry bands on polluted insulation. Proc. Inst. Electr. Eng. 1968, 115, 1707-1712. [CrossRef]

35. Waters, R.T. Formation and characterization of dry bands in clean fog on polluted insulators. IEEE Trans. Dielectr. Electr. Insul. 1999, 6, 714-731.

36. Mekhaldi, A.; Namane, D.; Bouazabia, S.; Beroual, A. Flashover of discontinuous pollution layer on HV insulators. IEEE Trans. Dielectr. Electr. Insul. 1999, 6, 900-906. [CrossRef]

37. Jiang, X.; Wang, S.; Zhang, Z.; Hu, J.; Hu, Q. Investigation of flashover voltage and non-uniform pollution correction coefficient of short samples of composite insulator intended for $\pm 800 \mathrm{kV}$ UHVDC. IEEE Trans. Dielectr. Electr. Insul. 2010, 17, 71-80. [CrossRef]

38. Waters, R.T.; Haddad, A.; Griffiths, H.; Harid, N.; Sarkar, P. Partial-arc and spark models of the flashover of lightly polluted insulators. IEEE Trans. Dielectr. Electr. Insul. 2010, 17, 417-424. [CrossRef]

39. Slama, M.E.-A.; Beroual, A.; Hadi, H. Influence of non-uniformity of pollution thickness on insulator flashover under impulse voltage. In Proceedings of the 2010 International Conference on High Voltage Engineering and Application (ICHVE), New Orleans, LA, USA, 11-14 October 2010; pp. 528-531.

40. Slama, M.E.-A.; Beroual, A.; Hadi, H. Influence of the linear non-uniformity of pollution layer on the insulator flashover under impulse voltage-estimation of the effective pollution thickness. IEEE Trans. Dielectr. Electr. Insul. 2011, 18, 384-392. [CrossRef]

41. Zhou, J.; Gao, B.; Zhang, Q. Dry band formation and its influence on electric field distribution along polluted insulator. In Proceedings of the 2010 Asia-Pacific Power and Energy Engineering Conference, Chengdu, China, 28-31 March 2010; pp. 1-5.

42. Arshad; Nekahi, A.; McMeekin, S.G.; Farzaneh, M. Effect of dry band location on electric field distribution along a polymeric insulator under contaminated conditions. In Proceedings of the 2015 50th International Universities on Power Engineering Conference (UPEC), Stoke on Trent, UK, 1-4 September 2015; pp. 1-4.

43. Arshad; Nekahi, A.; McMeekin, S.G.; Farzaneh, M. Influence of dry band width and location on flashover characteristics of silicone rubber insulators. In Proceedings of the Electrical Insulation Conference (EIC), Montreal, QC, Canada, 19-22 June 2016.

44. International Electrotechnical Commission (IEC). Artificial Pollution Tests on High Voltage Insulators to Be Used on AC Systems; International Standard; IEC: Geneva, Switzerland, 1991.

45. Gutman, I.; Dernfalk, A. Pollution tests for polymeric insulators made of hydrophobicity transfer materials. IEEE Trans. Dielectr. Electr. Insul. 2010, 17, 384-393. [CrossRef]

46. Feier-Iova, S.; Hinrichsen, V. Partial discharge inception voltage of water drops on insulating surfaces stressed by electrical field. In Proceedings of the 2009 IEEE Electrical Insulation Conference, Montreal, QC, Canada, 31 May-3 June 2009; pp. 21-25.

47. Ishii, M.; Akbar, M.; Kawamura, T. Effect of ambient temperature on the performance of contaminated DC insulators. IEEE Trans. Electr. Insul. 1984, 2, 129-134. [CrossRef]

48. Karady, G.G.; Shah, M.; Brown, R.L. Flashover mechanism of silicone rubber insulators used for outdoor insulation-I. IEEE Trans. Power Deliv. 1995, 10, 1965-1971. [CrossRef]

49. Shah, M.; Karady, G.G.; Brown, R.L. Flashover mechanism of silicone rubber insulators used for outdoor insulation-II. IEEE Trans. Power Deliv. 1995, 10, 1972-1978. [CrossRef]

50. Nazir, M.T.; Jiang, X.; Akram, S. Laboratory investigation on hydrophobicity of new silicon rubber insulator under different environmental conditions. Int. J. Electr. Comput. Sci. 2012, 12, 1. 
51. Li, Z.; Liang, X.; Zhou, Y.; Tang, J.; Cui, J.; Liu, Y. Influence of temperature on the hydrophobicity of silicone rubber surfaces [outdoor insulator applications]. In Proceedings of the 2004 Annual Report Conference on Electrical Insulation and Dielectric Phenomena, Boulder, CO, USA, 17-20 October 2004; pp. 679-682.

52. Taheri, S.; Farzaneh, M.; Fofana, I. Electrical performance evaluation of EHV post insulators covered with ice under different air gap configurations. IEEE Trans. Dielectr. Electr. Insul. 2014, 21, 2619-2627. [CrossRef]

(c) 2016 by the authors; licensee MDPI, Basel, Switzerland. This article is an open access article distributed under the terms and conditions of the Creative Commons Attribution (CC-BY) license (http://creativecommons.org/licenses/by/4.0/). 